\title{
DESIGNING AND FABRICATION OF COMPRESSED AIR ENGINE
}

\author{
Jadupati Bhakat ${ }^{1}$, Mukul Gupta ${ }^{2}$, Gummadi Gokul Manikanta ${ }^{3}$, Lalit Sai G ${ }^{4}$, \\ Mentor Mragank Sharma ${ }^{5}$ \\ ${ }^{1,2,3,4,5}$ Amity School of Engineering and Technology, Lucknow, Uttar Pradesh- 227105
}

\begin{abstract}
In modern era most of the vehicles uses combustible hydrocarbons as fuels (petrol, diesel, gasoline etc.). With the increase in number of vehicle the rate of fuel consumption also increases. These fuels are non-renewable source of energy, which means we have limited reserve and the resources may deplete after few years, the further hike in number of vehicles may shift the year closer. So we need to find an alternative method else there will be no sources left to drive the vehicle. Nowadays electric powered vehicles are in demand but the problem with electric powered vehicles is that they take too much time to get charged (4-6 hours) which means more consumption of electricity. In order to avoid this problem there is one more concept in which compressed air is used. Air is abundant in nature and is renewable source of energy; moreover in case of vehicles running on combustible hydrocarbons pollutes the environment by discharging exhaust toxic gases after burning the fuel inside the engine chamber. So, pollution is also a factor for which we need to limit the use of fuel. As pollution is a reason for global warming. In case of compressed air technique we need not to burn anything, so there is no question of pollution. Compressed air technique is totally pollution free and use of renewable resource makes it further reliable and economical. Thus compressed air technology can be the future of mankind. That is the reason many scientists are still researching on this topic.
\end{abstract}

Keywords: Compressed Air Engine, Compressed Air Technology, Compressed Air Technique $* * *$

\section{INTRODUCTION}

Compressed air is just the normal air but having pressure more than the ambient atmospheric pressure (1.01325bar). Compressed air has potential energy with it. When compressed air is allowed to expand freely it does work. This property of the compressed air can be employed to fetch useful mechanical work.

\section{DESIGN AND FABRICATION}

\section{Compressed air bicycle}

In order to build a compressed air bicycle the following components are required:

1) Pressure vessel: a pressure vessel is a cylindrical tank (may also exist in other shapes, most common shapes are spherical and cylindrical) which withholds liquid and gases having pressure more than the ambient air pressure. Pressure vessel has valves which regulates the flow of Compressed air. Figure 1 shows a pressure vessel. $^{[1][2][3]}$

2) Air impact wrench: it is a type of pneumatic motor which gives rotary motion as an output when compressed air is fed to it. It delivers high torque output. The working principle behind this is that there is a free hammer spinning inside the wrench which strikes the anvil and makes it rotate with a high torque value. This working mechanism is known as hammer mechanism. Figure 2 shows an air impact wrench. ${ }^{[4][5]}$

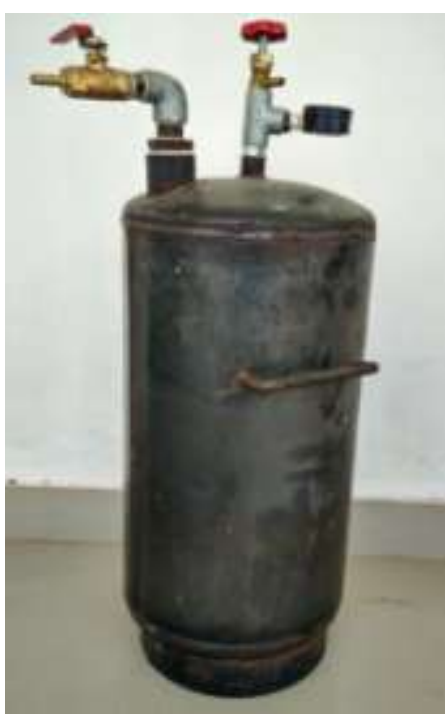

Figure 1. Pressure vessel

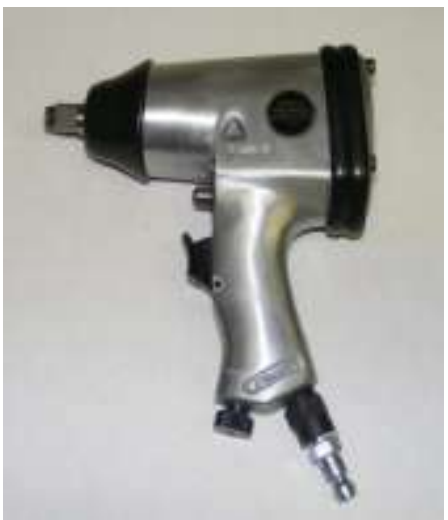

Figure 2. Air impact wrench 
3) Spur gear: A gear is a rotating circular disc having cut teeth, which meshes with another toothed part to transmit torque. The teeth of spur gear are radially projected. The edge of each tooth is straight and is aligned parallel to the axis of rotation. Figure 3 shows a spur gear. ${ }^{[6][7]}$

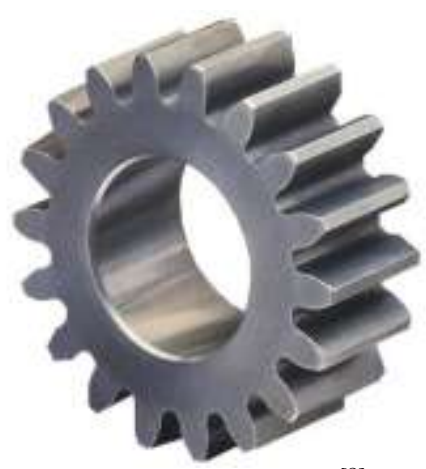

Figure 3. Spur gear ${ }^{[8]}$

There are two spur gears one having 40 teeth and other is having 20 teeth. The gear having less number of teeth is known as pinion and the other one is known as the gear. The pinion is fixed with the output spindle of the air impact wrench and the gear is fixed with the rear wheel of the bicycle. The two gears are then meshed; the pinion is the driving gear which drives the gear attached with the wheel. As the size of driven gear is bigger than that of driving gear, torque on the wheel increases. In case if the driven gear is smaller and the driving gear, rpm of the driven gear increases. Figure 4 shows the assembly. The compressed air is fed to the air impact wrench through regulating pipes. The pressure vessel rests over the bicycle carriage. Inside the pressure vessel there is compressed air. The compressed air when goes inside the air wench, by hamming mechanism it generates high torque output on the spindle and also on the pinion attached to it. The further increases the torque on the wheel as the gear on the wheel is meshed with the pinion. Thus this is how the bicycle moves forward. Figure 5 show a compressed air bicycle.

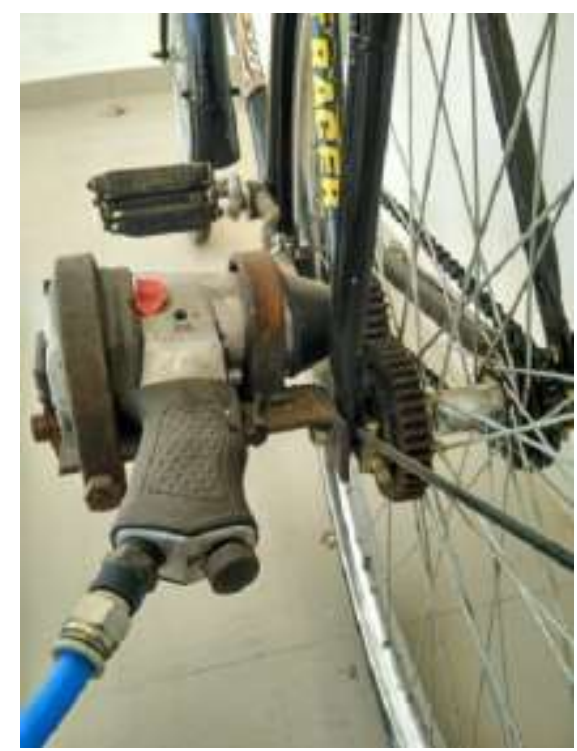

Figure 4. Gear and pinion assembly

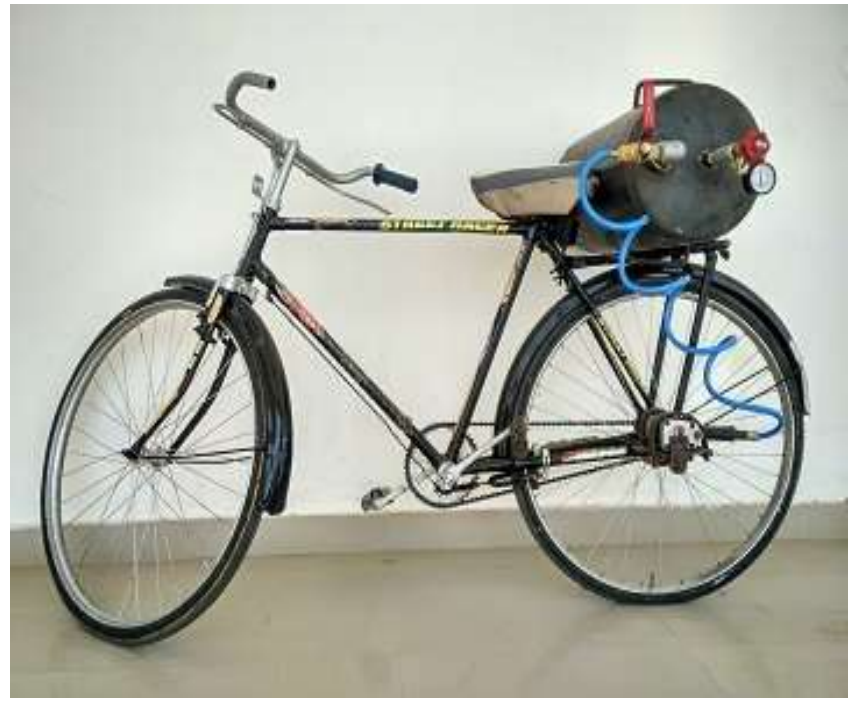

Figure 5. Compressed Air Bicycle

\section{COMPRESSED AIR ENGINE}

In this the compressed air will be stored in a tank and then it will be fed inside the engine chamber. Inside the air chamber there is a piston which will be mounted over a spring. When the compressed air will be fed inside the chamber it will expand and will do work over the piston to push it down. Hence the spring will get compressed. When the air will escape from the camber the force over the top of the piston will be zero and then the spring will push the piston upward. This is how the piston will start reciprocating. The reciprocating piston will help in rotating the crankshaft by the crankshaft mechanism. Figure 6 shows a compressed air engine.

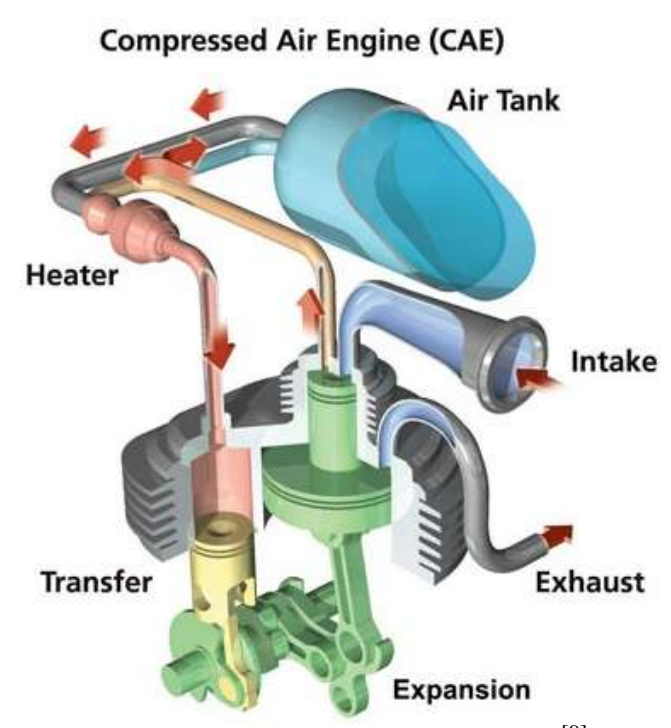

Figure 6. Compressed air engine ${ }^{[9]}$

\section{ADVANTAGES}

The advantages of using the compressed air technology are as follows:

1) Pollution free process

2) Uses renewable source of energy. 
3) Saves electricity and fossil fuels.

4) In compared with electric powered vehicles electricity is only consumed in compressing the air.

5) Cost of compressed air is relatively very low than petrol, diesel and gasoline.

6) The maintenance cost is very low.

7) It reduces the overall cost of the vehicle as ignition system, cooling system and exhaust system are not required.

\section{APPLICATION}

1) This concept can replace common combustible engines as it is environmental friendly and very reliable.

2) The wheelchairs can be made by this concept. In comparison with normal wheelchair it can reduce mechanical effort of pushing the wheelchair whereas in case of electric wheelchair it reduces the consumption of electricity.

3) The escalators in the malls consume a huge amount of electricity as they are in continuous motion. Using of compressed air technology can help in saving a lot of electricity.

\section{LIMITATION}

Whenever there is any change in form of energy there are losses. In case of compressed air engine electrical energy is first converted into pressurized potential energy, potential energy is then converted into mechanical energy. Due to these transformations of energies there is a huge loss.

\section{FUTURE SCOPE}

Many automobile companies are making their effort in order to build compressed air vehicle. Research is going in order to cope up with the losses that are coming due to transformation of energy. Compressed air could be the best alternative in order to drive vehicles in future.

\section{CONCLUSION}

Nowadays we have continuous need of energy is increasing, but basically conventional source of energy is very limited due to this the rate on price of petroleum is hiked day by day. To satisfy there need alternate fuel or energy is required. But while considering alternate fuel some of factors are to be considered like availability, economy, and environmental friendly etc., based on that Compressed Air Technology is best technology which tend engine to zero pollutions. If further improvement is carried out with stress analysis, thermodynamic analysis, minimize compressed energy loss and other losses.

\section{REFERENCES}

[1] A.C. Ugural, S.K. Fenster, Advanced Strength and Applied Elasticity, 4th ed.

[2] E.P. Popov, Engineering Mechanics of Solids, 1st ed.

[3] Megyesy, Eugene F. "Pressure Vessel Handbook, 14th Edition." PV Publishing, Inc. Oklahoma City, OK.
[4] TechOne: Basic automotive service and maintenance By Don Knowles, Jack Erjavec.

[5] outdoor power equipment (ED version) by Jay Webster, published by Cengage learning, 2000.

[6] http://www.merriam- webster.com/dictionary/gear

[7] Transmission Basics". HowStuffWorks.

[8] http://www.traceygear.com/images/Spur2.jpg

[9] http://contest.techbriefs.com/images/stories/entries201 3/20130306013350_cae1.jpg 